\title{
Bilateral Arm Training for Patients with Chronic Hemiparetic in Upper Limb Function
}

\author{
Ángel Sánchez Cabeza ${ }^{1}$ and Patricia Ruíz de Martín Esteban Corral ${ }^{2, *}$ \\ ${ }^{1}$ Hospital Universitario Fundación Alcorcón, Madrid, Spain \\ ${ }^{2}$ Centro de Atención Integral a Personas Con Daño Cerebral Polibea, Madrid, Spain
}

\begin{abstract}
Assess the effect that BAT (Bilateral Arm Training) produces on the upper limb motor control in patients with chronic brain injury assessed by the Wolf Motor Function Test (WMFT). Assess if there is a statistically significant correlation between motor control improvement and disability perceived by the Quick Dash questionnaire application. A quasi-experimental study with pre-post treatment measures during three months was performed in a sample of twelve patients with chronic brain injury. Patients received twelve sessions of forty-five minutes from bilateral training with a frequency of three times per week. WMFT and QD were used for the procedure assessment. Outcomes were statistically analyzed by the SPSS v 17.0 software. The study was executed at Polibea. Study's inclusion criteria were as follows: no serious cognitive deficits, one or both upper limb's control motor affected, attend to Polibea two times per week and no sensitive aphasia.

After the BAT treatment we observed a statistically significant difference on motor control improvement in the WMFT. However the disability perceived through QD was not statistically significant. In conclusion, BAT improves motor control in our patients with chronic acquired brain injury.
\end{abstract}

Keywords: Bilateral arm training, Brain injury, Acquired brain injury, Occupational therapy, Upper limb.

\section{INTRODUCTION}

About $70 \%-80 \%$ of patients who have suffered brain damage present alterations in motor control of the upper extremity (UE). Some of them will be unable to use their affected arm in daily life activities. It is estimated that between $25 \%$ and $53 \%$ of patients at six months after suffering a stroke, present levels of functional dependence to perform some activities of their daily life [1-2].

Stroke survivors are often left with hemiplegia or hemiparesis of the UE that makes functioning in their daily life environment extremely challenging. The disruptions caused to motor control of the UE by acquired brain injury are persistent despite usual treatment, and thus, novel intervention techniques are demanded. Among the approaches advocated for brain injury motor rehabilitation, Bilateral Arm Training (BAT) has received considerable attention. BAT is based on motor learning principles, including repetition, feedback and goal setting with the aim of overcoming learning nonuse and relative inactivity, but also includes use of non-paretic arm as a fundamental component of the training based on inter-limb coupling theory where the 2 arms act to form a "neuro-functional" unit [3-9]. Mudie [10] described BAT as: "simultaneous bilateral training that involves the execution of identical activities with both arms simultaneously but independently".

*Address correspondence to this author at the Centro de Atención Integral a Personas Con Daño Cerebral Polibea, Madrid, Spain;

Tel/Fax: 0034916890790; E-mail: patriciarmec@gmail.com
Beneficial effects of BAT are assumed to arise from an inter-limb coupling effect, in which movement of the non-paretic arm facilitates movements in the impaired limb. Bilateral practice of synchronous movements with the paretic and non-paretic limbs allows activation of the intact hemisphere to facilitate activation of the damaged hemisphere through enhanced interhemispheric inhibition.

Symmetrical bilateral movements activate similar neural networks in both hemispheres when homologous muscle groups are simultaneously activated. Bilateral symmetrical movements therefore, may allow for the activation of the undamaged hemisphere, thus promoting neural plasticity to increase activation of the damaged hemisphere and facilitate movement control of the impaired limb [8]. After acquired brain injury have shown alterations to the inter-hemispheric inhibitory capacity and difficulties affecting the implementation of the motor control that prevent the functional use of the upper extremity.

Most activities of daily living are performed involving the use of both upper extremities (dressing, feeding, grooming, make a bed, etc), although some of these activities during implementation are carried out unilaterally which largely depends on related factors such as: characteristics of the object, this position in space, where the task context and the subject's ability to perform it occurs, among others.

The most difficult motor control activities are performed by the dominant upper extremity, while the 
simplest are performed by any limb. There are different types of bilateral activities: bilateral symmetrical activities, contrary bilateral activities, and bilateral supplementary activities [11-15].

This technique involves active patient participation for finding solutions related to the improvement of motor control, as well as proper design of therapeutic activities tailored to the sensory and motor characteristics of the patient in order to stimulate motor learning and functionality.

\section{PARTICIPANTS AND METHOD}

\section{Design}

A quasi-experimental study with pre-post treatment measures was performed between February to May of 2013.

A total of twelve hemi-paretic patients received twelve sessions of forty-five minutes of BAT three times per week during three months.

Participants' characteristics are summarized in Table 1. The study was executed at Polibea. Study's inclusion criteria were as follows: no serious cognitive deficits (evaluated by neuropsychology department), one or both upper limb's control motor affected, attend to Polibea two times per week and no sensitive aphasia.

All participants authorized their collaboration by signing an informed consent where the procedure and methodology of the sessions was explained.

\section{Functional Assessment/Instruments and Measures}

The methods used to quantify the results obtained with the upper limb were Wolf Motor Function Test and QuickDash.

The WMFT is a function-based motor assessment of 17 tasks, including 15 timed and functional ability tasks and 2 strength tasks. The WMFT has established high reliability and validity in brain injury patients. This test was designed to assess the motor ability of patients with moderate to severe upper extremity motor deficits. The WMFT has been found to be useful for the characterizing the motor status of chronic patients from a population of higher functioning individuals with stroke and traumatic brain injury, in terms of severity and upper extremity motor deficit.

The QuickDash is scored in two components: the disability/symptom section (11 items, scored 1-5) and the optional high performance sport/music or work modules (four items, scored 1-5), the items measure

Table 1: Demographic and Clinical Characteristics of the Participants

\begin{tabular}{|c|c|c|c|c|c|c|}
\hline PATIENT & AGE & $\begin{array}{c}\text { TIME SINCE } \\
\text { STROKE (years) }\end{array}$ & $\begin{array}{l}\text { TYPE/SIDE OF } \\
\text { LESION }\end{array}$ & LESION & WOLF SCORE & GENDER \\
\hline BAT 1 & 46 & 4 & $\mathrm{R}$ (vascular) & Unilateral & $\mathrm{R}: 22 / 96$ & Male \\
\hline BAT 2 & 41 & 4 & $\mathrm{R}_{++} \& \mathrm{~L}$ (vascular) & Bilateral & $\begin{array}{l}R: 53 / 96 \\
L: 66 / 96\end{array}$ & Male \\
\hline BAT 3 & 31 & 5 & $\mathrm{R}$ (vascular) & Unilateral & $\mathrm{R}: 48 / 96$ & Male \\
\hline BAT 4 & 49 & 3 & L (vascular) & Unilateral & $\mathrm{L}: 38 / 96$ & Female \\
\hline BAT 5 & 48 & 4 & L (vascular) & Unilateral & L: 29/96 & Male \\
\hline BAT 6 & 34 & 3 & L (traumatic) & Unilateral & L: 65/96 & Female \\
\hline BAT 7 & 34 & 3 & $\mathrm{R}++\& \mathrm{~L}$ (vascular) & Bilateral & $\begin{array}{l}R: 91 / 96 \\
L: 95 / 96\end{array}$ & Female \\
\hline BAT 8 & 29 & 8 & $\mathrm{R}++\& \mathrm{~L}$ (traumatic) & Bilateral & $\begin{array}{l}R: 51 / 96 \\
L: 59 / 96\end{array}$ & Male \\
\hline BAT 9 & 54 & 6 & $\mathrm{R}++\& \mathrm{~L}$ (traumatic) & Bilateral & $\begin{array}{l}R: 96 / 96 \\
L: 95 / 96\end{array}$ & Male \\
\hline BAT 10 & 41 & 7 & R (traumatic) & Unilateral & $R: 46 / 96$ & Male \\
\hline BAT 11 & 56 & 3 & $\mathrm{R}++\& \mathrm{~L}$ (vascular) & Bilateral & $\begin{array}{l}\text { R: 83/96 } \\
\text { L: 86/96 }\end{array}$ & Male \\
\hline BAT 12 & 55 & 2 & L (vascular) & Unilateral & L: $17 / 96$ & Female \\
\hline
\end{tabular}

R: right upper limb. L: left upper limb. 
physical function and symptoms in persons with any or multiple musculoskeletal disorders of the upper limb. This shortened version provides clinicians faster measurement of disability and symptoms.

Twelve sessions of BAT were performed getting pre and post treatment results in order to identify changes in the upper arm function and patient's perception of his own disability.

\section{Intervention/ Interference}

An individualized activities program was designed based on the outcomes obtained in the pre-treatment evaluation. This program was modified as patients managed specific targets according to the motor control trained improvement.

In general, activities are classified into: symmetrical tasks, where both upper extremities perform same target at the same time, contrary tasks, in which the movements are the same but requested performed antagonistically in the direction of movement, whether they be simultaneously or one after the other, and complementary tasks, where motor action of one limb is needed for the motor performance of the other.

The materials used were everyday items of different types such as towels, cubes of different sizes, lentils, marbles, beach sand, fabrics of different sizes and textures, balls, pins, cups, spoons, clothespins and therapeutic putty, among others, and in general any object that would stimulate the target movement for improvement of motor control.

\section{Statistical Analysis}

In order to identify the effects of treatment on the motor control were carried out parametric methods for comparing two measurements, Student $t$ test for related samples. The Pearson correlation coefficient was used to study relationships between WMFT and QD. The analysis of the results was performed using the statistical analysis program SPSS version 17.0, taking a confidence interval of $95 \%$. All data met the criteria of normality, so that, the analysis was performed using statistical parametric. A value of $p$ $<0.05$ was considered statistically significant.

\section{RESULTS}

The data obtained after the intervention is done indicate the existence of a number of changes in the selected variables. The results of WMFT (Table 2) using the t-student test and considering the scores of the right upper extremity (ScoreR1-ScoreR2) and the left upper extremity (ScoreL1-ScoreL2) before and after the treatment reveal statistically significant data to both limbs $(p=0,006)$, indicating the existence of motor control improvement after intervention (Table 3).

The analysis of the scores obtained in the QD before and after intervention (Table 4) does not show statistically significant results $(p=0$ '73), which indicates that the perception of the patient's disability was not changed after treatment (Table 5). However, it is important to note that on average patients experienced improvement related to the degree of perceived disability (Table 6).

Table 2: Outcomes with Pre - to Post- Values of each Arm before (WMFT I) and after (WMFT II) BAT

\begin{tabular}{|c|c|c|}
\hline PACIENT & WMFT I & WMFT II \\
\hline BAT 1 & $\mathrm{R}: 22 / 96$ & R:27 /96 \\
\hline BAT 2 & R: 53/96 L: 66/96 & $\mathrm{R}: 61 / 96$ L:76 /96 \\
\hline BAT 3 & R: $48 / 96$ & $R: 63 / 96$ \\
\hline BAT 4 & $L: 38 / 96$ & $\mathrm{~L}: 41 / 96$ \\
\hline BAT 5 & L: 29/96 & L:31 /96 \\
\hline BAT 6 & L: 65/96 & L: 78/96 \\
\hline BAT 7 & R: 91/96 L: 95/96 & R: 96/96 L:96/96 \\
\hline BAT 8 & R: 51/96 L: 59/96 & R: 61/96 L:73/96 \\
\hline BAT 9 & R: $96 / 96$ L: 95/96 & R:96 /96 L:96/ 96 \\
\hline BAT 10 & $R: 46 / 96$ & $\mathrm{R}: 48 / 96$ \\
\hline BAT 11 & R: 83/96 L: 86/96 & R:96 /96 L:91 /96 \\
\hline BAT 12 & L: $17 / 96$ & L:24 /96 \\
\hline
\end{tabular}

R: right upper limb. L: left upper limb. 
Table 3: Statistically Outcomes for WMFT

\begin{tabular}{|c|c|c|c|c|c|}
\hline \multicolumn{7}{|c|}{ Paired Samples Statistics } \\
\hline \multirow{2}{*}{ Pair 1 } & Mean & N & Std. Deviation & Std. Error Mean \\
& SCORER1 & 61,25 & 8 & 25,877 & 9,149 \\
\cline { 2 - 6 } & SCORER2 & 68,50 & 8 & 25,506 & 9,018 \\
\hline \multirow{2}{*}{ Pair 2 } & SCOREL1 & 61,11 & 9 & 28,440 & 9,480 \\
& SCOREL2 & 67,33 & 9 & 28,098 & 9,366 \\
\hline
\end{tabular}

\begin{tabular}{|c|c|c|c|c|}
\hline \multicolumn{2}{|c|}{ Paired Samples Correlations } & Correlation & Sig. \\
\hline \hline Pair 1 & SCORER1 \& SCORER2 & 8 &, 979 &, 000 \\
\hline Pair 2 & SCOREL1 \& SCOREL2 & 9 &, 984 &, 000 \\
\hline
\end{tabular}

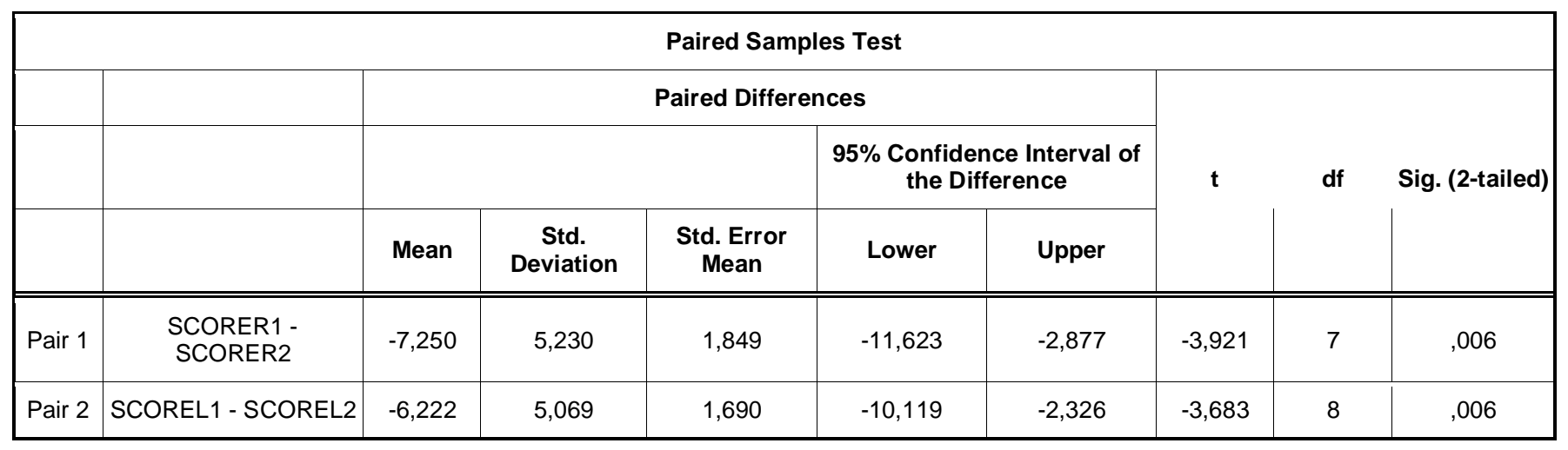

Table 4: Outcomes with Pre- to Post- Values of each Arm before (QD1) and after (QD2) BAT

\begin{tabular}{|c|c|c|}
\hline PACIENT & QD 1 & QD 2 \\
\hline \hline BAT 1 & 54,5 & 59 \\
\hline BAT 2 & 52,2 & 27,3 \\
\hline BAT 3 & 31,8 & 81,8 \\
\hline BAT 4 & 77,3 & 52,3 \\
\hline BAT 5 & 38,6 & 29,5 \\
\hline BAT 6 & 25 & 11,3 \\
\hline BAT 7 & 18,2 & 41,2 \\
\hline BAT 8 & 56,8 & 18,2 \\
\hline BAT 9 & 31,8 & 52,3 \\
\hline BAT10 & 38,6 & 13,6 \\
\hline BAT 11 & 25 & 56,8 \\
\hline BAT 12 & 61,4 & \\
\hline
\end{tabular}


Table 5: Statistically Outcomes for QD

\begin{tabular}{|c|c|c|c|c|c|}
\hline \multicolumn{7}{|c|}{ PairedSamplesStatistics } \\
\hline \multirow{2}{*}{ Pair 1 } & Mean & N & Std. Deviation & Std. Error Mean \\
\cline { 2 - 6 } & SCORE1 & 42,600 & 12 & 17,7690 & 5,1295 \\
& SCORE2 & 41,608 & 12 & 21,7149 & 6,2685 \\
\hline
\end{tabular}

\begin{tabular}{|c|c|c|c|c|c|c|c|c|c|}
\hline \multicolumn{10}{|c|}{ PairedSamples Test } \\
\hline & & \multicolumn{5}{|c|}{ PairedDifferences } & \multirow{3}{*}{$\mathbf{t}$} & \multirow{3}{*}{ df } & \multirow{3}{*}{ Sig. (2-tailed) } \\
\hline & & \multirow{2}{*}{ Mean } & \multirow{2}{*}{$\begin{array}{c}\text { Std. } \\
\text { Deviation }\end{array}$} & \multirow{2}{*}{$\begin{array}{l}\text { Std. Error } \\
\text { Mean }\end{array}$} & \multicolumn{2}{|c|}{$\begin{array}{l}95 \% \text { Confidence Interval of } \\
\text { the Difference }\end{array}$} & & & \\
\hline & & & & & Lower & Upper & & & \\
\hline Pair 1 & $\begin{array}{l}\text { SCORE1 - } \\
\text { SCORE2 }\end{array}$ & ,9917 & 9,9994 & 2,8866 & $-5,3617$ & 7,3450 & ,344 & 11 & ,738 \\
\hline
\end{tabular}

Table 6: Statistically Medium Outcomes for QD

\begin{tabular}{|c|c|c|}
\hline \multicolumn{2}{|c|}{ Stadístics } \\
\hline \multicolumn{2}{|c|}{ Dif } \\
\hline \hline \multirow{2}{*}{$\mathrm{N}$} & Lvailable & 12 \\
\hline & Lost & 0 \\
\cline { 2 - 3 } & Mean &,- 9917 \\
\hline & Std. Deviation & $-1,5000$ \\
\hline
\end{tabular}

\begin{tabular}{|c|c|c|c|c|c|}
\hline \multicolumn{6}{|c|}{ Dif } \\
\hline & & Frecuency & Percentg & Valide Perctg & Cumultv.Perctg. \\
\hline \multirow{7}{*}{ Available } & $-13,60$ & 1 & 8,3 & 8,3 & 16,7 \\
\hline & $-6,90$ & 1 & 8,3 & 8,3 & 33,3 \\
\hline & $-4,60$ & 1 & 8,3 & 8,3 & 41,7 \\
\hline & $-4,50$ & 1 & 8,3 & 8,3 & 50,0 \\
\hline & 1,50 & 1 & 8,3 & 8,3 & 58,3 \\
\hline & 13,70 & 2 & 16,7 & 16,7 & 100,0 \\
\hline & Total & 12 & 100,0 & 100,0 & \\
\hline
\end{tabular}


Table 7: Outcomes for SPSS with Pearson correlation: WMFT y QD

\begin{tabular}{|c|c|c|c|c|}
\hline \multicolumn{5}{|c|}{ Correlations } \\
\hline & & SCORER2 & SCOREL2 & SCORED2 \\
\hline \multirow[t]{3}{*}{ SCORER2 } & Pearson Correlation & 1 & ,978** &,$- 885^{* *}$ \\
\hline & Sig. (1-tailed) & & ,002 & ,002 \\
\hline & $\mathrm{N}$ & 8 & 5 & 8 \\
\hline \multirow[t]{3}{*}{ SCOREL2 } & Pearson Correlation &, $978^{* *}$ & 1 &,$- 792^{* *}$ \\
\hline & Sig. (1-tailed) &, 002 & &, 006 \\
\hline & $\mathrm{N}$ & 5 & 9 & 9 \\
\hline \multirow[t]{3}{*}{ SCORED2 } & Pearson Correlation &,$- 885^{* *}$ &,$- 792^{* *}$ & 1 \\
\hline & Sig. (1-tailed) &, 002 &, 006 & \\
\hline & $\mathrm{N}$ & 8 & 9 & 12 \\
\hline
\end{tabular}

${ }^{\star *}$ Correlation is significant at the 0.01 level (1-tailed).

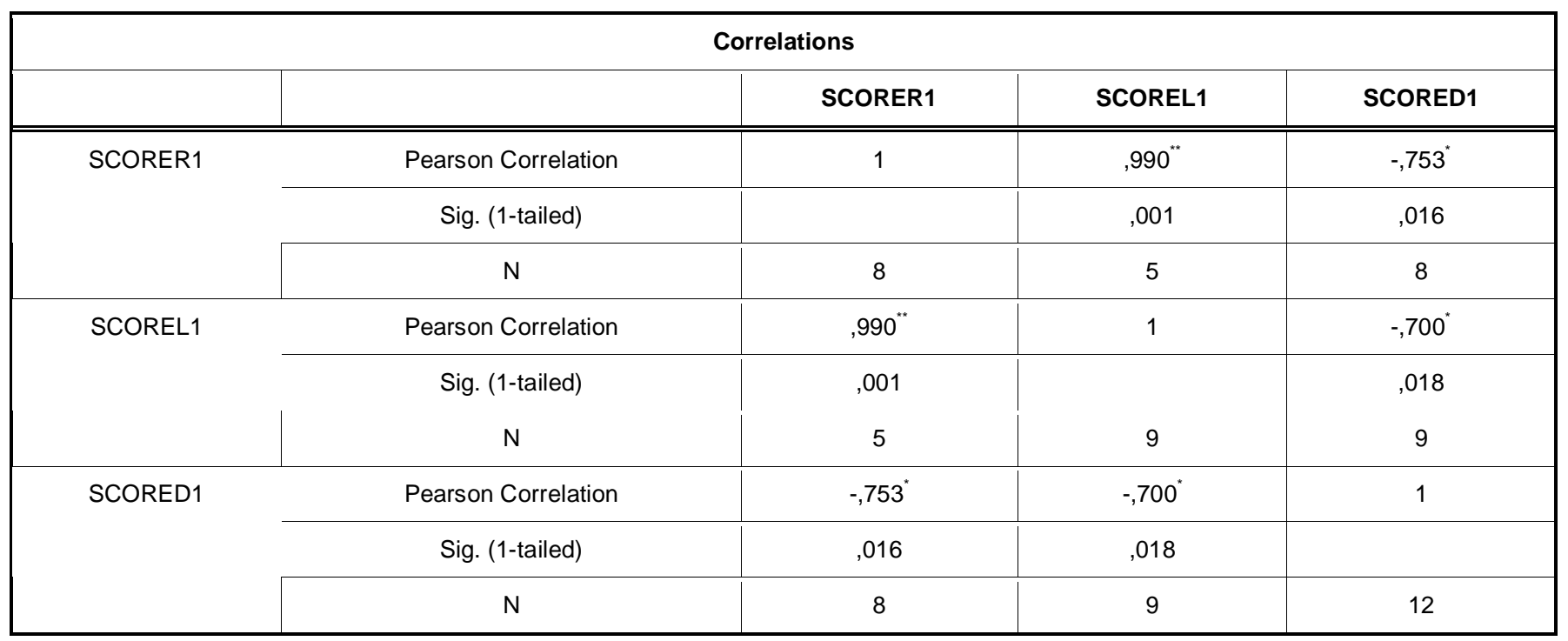

${ }^{* *}$ Correlation is significant at the 0.01 level (1-tailed)

${ }^{*}$ Correlation is significant at the 0.05 level (1-tailed).

The Pearson correlation coefficient (Table 7) relating the QD and WMFT scores before and after treatment shows decreasing rate, that is to say, the higher is the score on motor scale the lower is the score on the questionnaire (Figure 1). This fact could mean that the greater the degree of recovery of motor control is the best degree of perceived disability by patients who have received treatment.

\section{DISCUSSION}

The results of our study and clinical observations reflected in other research show that offering the patient the ability to move and have a greater awareness and knowledge of their paretic limb, can improve motor control of the affected extremity, fact which is particularly relevant when dealing with chronic patients [16].

Although studies on effectiveness of rehabilitation of the upper limb in patients who have suffered an acquired brain injury have not demonstrated the superiority of one technique versus another to achieve a significant improvement in the degree of functionality $[10,11,16-19]$, there are other authors who suggest that individuals with different levels of severity could benefit from bilateral upper extremity training. In cases of severe hemiparesis, where despite having not 


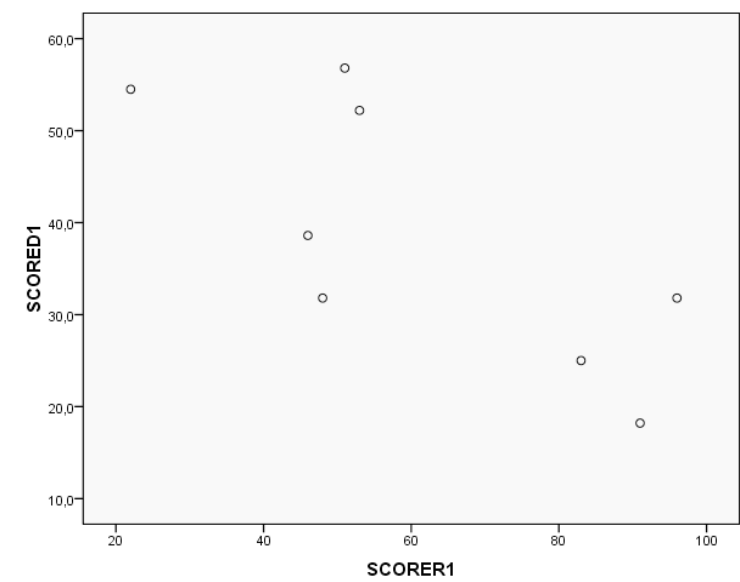

Figure 1: Graphic outcomes obtain for the WMFT y QD.

reached a clear and effective recovery, with functional objectives for the upper extremity, the fact of carrying out a treatment plan that values the potentials related to motor control of the upper extremity, and based on the bilateral training as a technique can help to achieve an improvement in the movement, greater involvement and functionality of the paretic limb in daily life [16].

Generally the subjects in our study evidenced two different patterns of motor behavior, on one hand those who could include their hand on the implementation of activities, and secondly, patients who had greater difficulty for hand motor control and had no capacity for active grip. So, for those patients who could use their paretic hand themselves in WMFT test (subtest related with spin cards, place a tower, take a pen or paperclip), during the reassessment, were observed changes that showed improvements in the quality and speed of movement, and other patients were able to use their hand despite not get to meet the motor planned target, reflecting quantitative improvements in the use of the upper limb. By contrast, in patients who could not include the hand paretic in the evaluation, nor in the processing activities, during treatment was observed an improvement of motor control of different joint segments, less tremor and increased participation for trained muscle groups while performing activities.

These variables related to the quality and the use of the upper limb while performing unilateral and bilateral activities have been extensively studied in previous research. Van der Lee et al. [20] found in a sample of sixty-six patients with chronic stroke that either forced use of the upper extremity and bilateral training produce changes in the amount and quality of the upper limb movement measured by the scales Motor Activity Log (amount of use) and Motor Activity Log

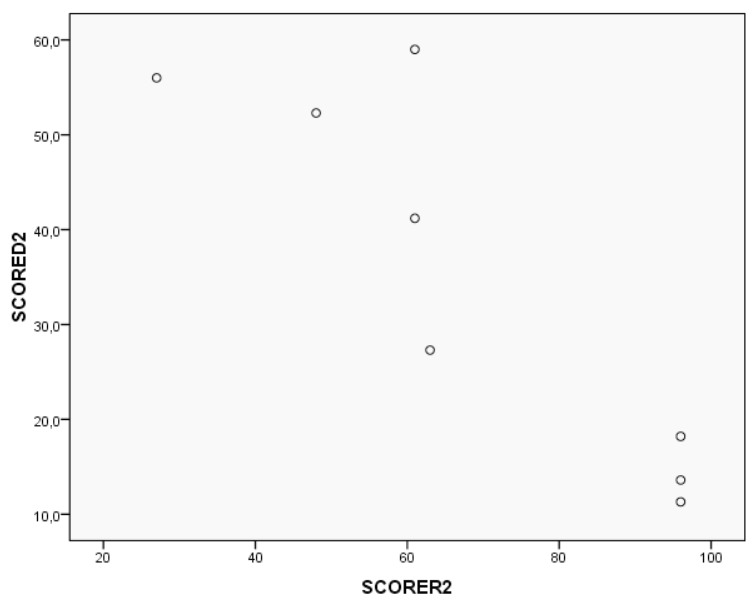

(quality of movement). These results revealed statistically significant differences in favor of the patient group that received forced use training of paretic upper extremity. In our study, the difference between the previous situation (lack of use) and bilateral training (increased use) could justify this fact.

At the beginning of the treatment some patients experienced moderate difficulties that decreased with the learning effect occurred during the execution of the activity. Subsequently motor control degrade when fatigue appeared, hence, the amount of practice was adapted to the individual needs of the study subjects in terms of three parameters related to the number of repetitions, five, ten or fifteen repetitions.

Qualitatively, in patients (cases 3, 6, 8, 11) who had previously shown some mobility in the upper limb but whose use was minimal or it could improve for the basic daily life activities, it was observed that after treatment the participation of their affected hand was higher but difficulties still persisted. Being chronic patients, this fact may be related with the phenomenon of "learned no use", which, based on a behavior modification process following the introduction of the injury in the central nervous system could mask a higher motor performance than the actual present.

Most patients when suffering injuries affecting the upper extremity end up using the most functional limb due to the continuous production of a negative feeling when using the paretic hand that may involve pain, increased effort, clumsiness, or negative emotional connotations when trying to carry out the activities This fact makes the good hand finally be the only option available after neurological injury. As in previous research [5] the subjects of our study, may have higher 
motor capacity than that measured in the initial evaluation if they exhibit "learned no use" which would explain an improvement when receiving enough practice by performing activities specifically designed for the motor control recovery. These activities involve the use of both limbs followed by positive reinforcement for achieving the targets of the treatment.

Another important aspect that has been observed during this research is that more than half of the patients improved their behavioral adherence along sessions showing higher involvement and motivation than in the initial evaluation. Clinical observation and patients' statements about motor training highlight this fact (cases 1, 2, 3, 5, 6, 7 8, 10 y 12). According to Lin et al. [21] this could be related to greater motivation for participation in activities aimed at therapeutic purposes which would increase the level of involvement of the patient on their recovery process.

The interpretation of the QD data shows different results, having patients whose perception of disability rating was better (cases 1, 3, 7, 8, 9, 11 and 12), against others whose scores after the intervention has been worse, i.e., their perception of disability had increased (cases 2, 4, 5, 6 and 10). There are no previous studies in patients with chronic hemiparesis in this sense that have been used QD test or valued through other instruments the degree of perceived disability. Existing research has focused on severe patients, which takes into account the emotional wellbeing and life quality [22] concluding that there is moderate evidence that bilateral training is not more effective than other treatments to improve emotional wellbeing assessed by the Hospital Anxiety and Depression Scale. In our study, we believe that encouraging greater awareness and better defined motor control difficulties by performing activities that previously the subject did not perform could contribute to the interpretation of data obtained. Thus, those patients who started from a better motor condition than they estimated it stands to reason that once treatment is over can experience more realistically motor possibilities of the upper extremity thereby decreasing the degree of perceived disability. However, those patients that treatment might have allowed them to better understand their limitations could have a negative effect on the perceived degree of disability.

\section{STUDY LIMITATIONS AND RECOMMENDATIONS}

Conducting this investigation there are several methodological difficulties to consider. The lack of a control group to compare the bilateral training would improve the interpretation of the effect that this technique might have on the motor control recovery of the upper extremity. Furthermore, the sample size $(n=$ 12 ) is small, making it difficult any generalization of the data.

Consider increasing the sample size and add a control group that enables randomization of groups to gain methodological quality and be able to more effectively interpret the data.

The search for a scale to assess and adapt in the best way possible to the wide spectrum of motor features of study patients is difficult, because on one hand a group of patients for some activities had a high degree of complexity (digital grip) while others require minimal difficulty. The great heterogeneity in relation to motor control experienced by patients with acquired brain injury and their evolution throughout the rehabilitation process influenced by multiple factors makes complex the process of selecting sample subjects. Given these characteristics, in future research it would be useful to introduce measures that assess the quality and quantity of upper extremity motor control, as well as assessments of the degree of independence in performing daily life activities.

\section{CONCLUSIONS}

The results of the study indicate that there is an improvement in the paretic limb motor control after application of bilateral training. Nevertheless, this aspect is not related to the degree of disability perceived by patients after intervention.

\section{DECLARATION OF CONFLICTING INTERESTS}

The authors declared no potential conflicts of interest with respect to the authorship and/or publication of this article.

\section{ACKNOWLEDGEMENT}

The authors thank the participants in this study and also the trainers and testers in the Polibea acquired brain injury Center who assisted with the testing and training.

\section{REFERENCES}

[1] Pang MY, Harris JE, Eng JJ. A community-based upperextremity group exercise program improves motor function and performance of functional activities in chronic stroke: a randomized controlled trial. Arch Phys Med Rehabil 2006; 87(1): $1-9$.

http://dx.doi.org/10.1016/j.apmr.2005.08.113 
[2] Wu C-Y, Hsieh Y-W, Lin K-C, Chuang L-L, Chang Y-F, Liu $\mathrm{H}-\mathrm{L}$, et al. Brain reorganization after bilateral arm training and distributed constraint-induced therapy in stroke patients: a preliminary functional magnetic resonance imaging study. Chin Med J 2010; 33: 628-637.

[3] Metrot J, Mottet D, Hauret I, van Dokkum L, HueiYuneBonnin-Koang, Torre $\mathrm{K}$, et al. Changes in bimanual coordination during the first 6 weeks after moderate hemiparetic stroke. Neurorehabil Neural Repair 2013; 27: 251-9.

http://dx.doi.org/10.1177/1545968312461072

[4] Lin K-C, Chen Y-A, Chen C-L, Wu C-Y, Chang Y-F. The effects of bilateral arm training on motor control and functional performance in chronic stroke: a randomized controlled study. Neurorehabil Neural Repair 2010; 24(1): 4251. http://dx.doi.org/10.1177/1545968309345268

[5] Whitall J, McCombe Waller S, Sorkin J, Forrester L, Macko $\mathrm{R}$, Hanley D, et al. Bilateral and unilateral arm training improve motor function through differing neuroplastic mechanisms: a single-blinded randomized controlled trial. Neurorehabil Neural Repair 2011; 25(2): 118-129. http://dx.doi.org/10.1177/1545968310380685

[6] Whitall J, McCombe Waller S, Silver K, Richard F. Repetitive bilateral arm training with rhythmic auditorycueing improves motor function in chronic hemiparetic. American Heart Association MD Stroke 2000; 31: 2390-5.

[7] Reistetter T, Abreu B, Bear-Lehman J, Ottenbacher $\mathrm{K}$. Unilateral and bilateral upper extremity weight-bearing effect on upper extremity impairment and functional performance after brain injury. Occup Ther Int 2009; 16(3-4): 218-231. http://dx.doi.org/10.1002/oti.278

[8] McCombe S, Whitall J. Bilateral arm training: Why and who benefits? NeuroRehabilitation 2008; 23(1): 29-41.

[9] Cauraugh JH, Summers JJ. Invited commentary on "effects of forced use on arm function in the subacute phase after stroke: a randomized, clinical pilot study." J Phys Ther 2009; 89: 539-541.

[10] Mudie $\mathrm{MH}$, Matyas TA. Can simultaneous bilateral movement involve the undamaged hemisphere in reconstruction of neural networks damaged by stroke? Disabil Rehabil 2000; 22: 23-37. http://dx.doi.org/10.1080/096382800297097

[11] Luft AR, McCombe-Waller S, Whitall J, et al. Repetitive bilateral arm training and motor cortex activation in chronic stroke: a randomized controlled trial. JAMA 2004; 292: 185361. http://dx.doi.org/10.1001/jama.292.15.1853
[12] Tseng YW, Scholz JP. Unilateral vs. bilateral coordination of circle-drawing tasks. Acta Psychol 2005; 120: 172-198. http://dx.doi.org/10.1016/j.actpsy.2005.04.001

[13] Cauraugh J, Naik S, Lodha N, Coombes S, Summers J. Long-term rehabilitation for chronic stroke arm movements: a randomized controlled trial. Clin Rehabil 2011; 25(12): 10861096.

http://dx.doi.org/10.1177/0269215511410580

[14] Wolf SL, Thompson PA, Morris DM, et al. The EXCITE trial: attributes of the Wolf Motor Function Test in patients with subacute stroke. Neurorehabil Neural Repair 2005; 19: 194205. http://dx.doi.org/10.1177/1545968305276663

[15] Fritz S, Blanton S, Uswatte G, Taub E, Wolf S. Minimal detectable change scores for the Wolf Motor Function Test. Neurorehabil Neural Repair 2009; 23: 662-667. http://dx.doi.org/10.1177/1545968309335975

[16] Coupar F, Pollock A, van Wijck F, Morris J, Langhorne P. Simultaneous bilateral training for improving arm function after stroke. The Cochrane Library 2010; Issue 4.

[17] Summers JJ, Kagerer F, Garry MI, Hiraga C, Loftus A, Cauraugh J. Bilateral and unilateral movement training on upper limb function in chronic stroke patients: A TMS study. Can J Neurol Sci 2007; 76-82. http://dx.doi.org/10.1016/i.jns.2006.10.011

[18] Wu C-Y, Chuang L-L, Lin Keh-C, Chen H-C, Tsay P-K. Randomized trial of distributed constraint-induced therapy versus bilateral arm training for the rehabilitation of upperlimb motor control and function after stroke. Neurorehabil Neural Repair 2011; 25: 130-9. http://dx.doi.org/10.1177/1545968310380686

[19] Cauraugh JH, Kim SB, Duley A. Coupled bilateral movements and active neuromuscular stimulation: intralimb transfer evidence during bilateral aiming. Neurosci Lett 2005; 382: $39-44$

http://dx.doi.org/10.1016/j.neulet.2005.02.060

[20] Arlette D. Descripción de la terapia de restricción inducida: aplicabilidad en el context clinic. Revista Mexicana de neurociencia 2012; 13(4): 223-232.

[21] Lin K, Chen Y, Chen Ch, Wu Ch, Chang Y. The effects of bilateral arm training on motor control and functional performance in chronic stroke: a randomized controlled study. Neurorehabil Neural Repair 2010; 24(1): 42-51. http://dx.doi.org/10.1177/1545968309345268

[22] Morris J, Van Wijck F. Responses of the less affected arm to bilateral upper limb task training in early rehabilitation after stroke: a randomized controlled study. Arch Phys Med Rehabil 2008; 93(7): 1129-1137. http://dx.doi.org/10.1016/j.apmr.2012.02.025 